Izaak J. de Hulster

\title{
Figurines in Achaemenid Period Yehud
}

\author{
Jerusalem's History of Religion and Coroplastics in the Monotheism Debate
}

[Figurinen im achämenidischen Jehud. Die Religionsgeschichte Jerusalems und Koroplastik in der Monotheismus-Debatte.]

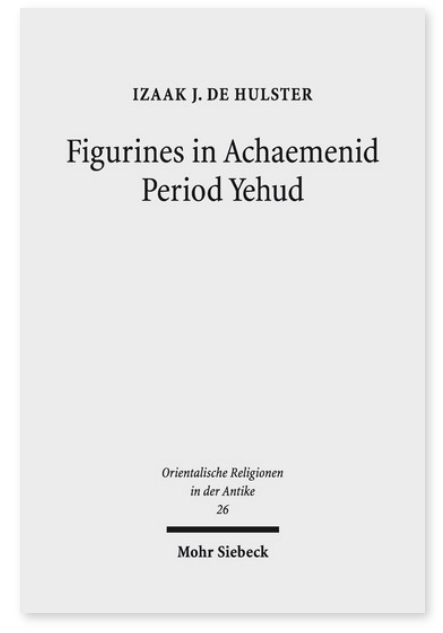

2017. XV, 225 Seiten. ORA 26

ISBN 978-3-16-155551-0

DOI 10.1628/978-3-16-155551-0

eBook PDF $134,00 €$

ISBN 978-3-16-155550-3

Leinen $134,00 €$
Veröffentlicht auf Englisch.

»In Jehud gab es Figurinen. « Izaak J. de Hulster geht dieser umstrittenen These nach und widerlegt den Forschungskonsens über das Fehlen von Figurinen in Jehud während der achämenidischen Zeit, insbesondere in Jerusalem. Dieser gründet sich auf die Annahme, dass Figurinen, die in Juda/Jehud ausgegraben wurden, auf die Eisenzeit II in dieser Region hinweisen (neben wenigen typologischen Ausnahmen). Ephraim Stern und andere haben dieses angebliche Fehlen von Figurinen als Hinweis auf Entstehung und Konsolidierung des jüdischen Monotheismus gedeutet. In seinem Werk entkräftet de Hulster dieses Paradigma mit einer detaillierten Studie der Figurinenfunde aus Yigal Shilohs Ausgrabung in der »Davidsstadt» (besonders deren Kontexte in Stratum 9) und bietet dabei ausreichend Belege der Existenz von Figurinen in Jerusalem nach 587/586. Der Autor widmet sich außerdem den Voraussetzungen des Paradigmas in der Archäologie, Geschichte, Religionsgeschichte, Theologie und der Exegese, und besonders in der Koroplastik.

Izaak J. de Hulster Born 1979; 2008 PhD (Utrecht); since 2014 University Researcher at the Faculty of Theology, University of Helsinki; 2017 Habilitation (Göttingen).

https://orcid.org/0000-0003-0706-4480
Jetzt bestellen:

https://mohrsiebeck.com/buch/figurines-in-achaemenid-period-yehud-9783161555510?no_cache=1 order@mohrsiebeck.com

Telefon: +49 (0)7071-923-17

Telefax: $+49(0) 7071-51104$ 